Habla su biblioteca

\title{
Nuestra herencia europea: ¿Educación para mujeres?
}

Katherine MilLer

Directora de Asuntos Culturales Biblioteca "Florentino Idoate, S. J."

Muchos [humanistas] estaban a favor de un entrenamiento intelectual sorprendente para mujeres, aunque todos pensaron que las madres no eran las personas apropiadas para dejar encargados los niños varones después de la edad de siete años.

Lawrence Stone, en el prefacio a Studies in Education During the Age of the Renaissance 1400-1600 por W.H. Woodward (New York, 1967), p. xiv. [traducción propia]
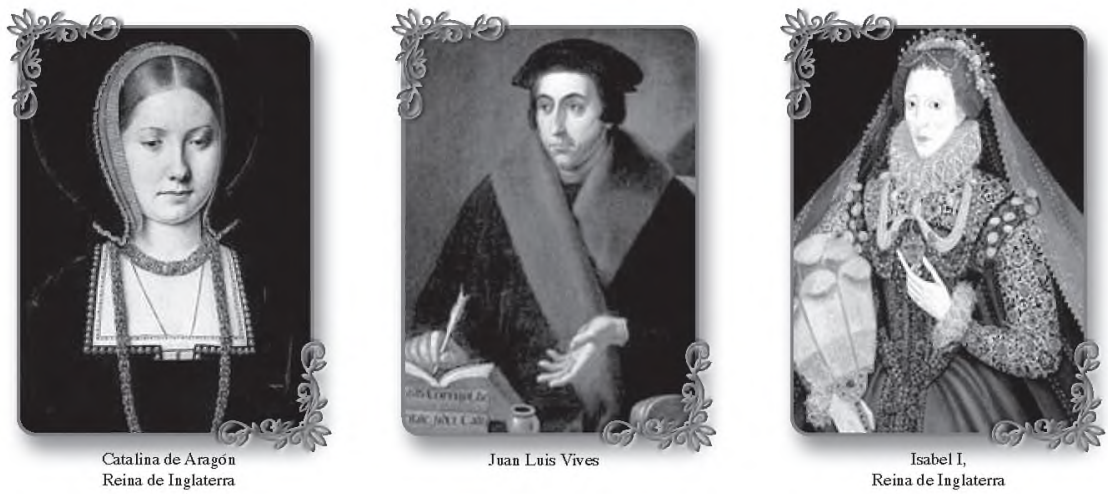
E gran auge del humanismo durante los renacimientos europeos glorificaba las capacidades del hombre y todas sus posibilidades por llegar a sus más altas esferas en literatura, filosofía, arte, gobierno y grandeza de toda índole. Pero la doctrina sobre la educación para mujeres es distinta.

La doctrina oficial de la Iglesia en Europa Occidental defendió la doctrina de que hombre y mujer fueron creados de igual manera en la imagen de Dios. Sin embargo, los metáforas y alegorías presentadas por los teóricos humanistas, especialmente en Inglaterra durante su Renacimiento en Humanismo Cristiano de los siglos XV-XVI, prestados casi verbatim por autores como Erasmo de Rótterdam, Dr. John Colet y Juan Luis Vives sugieren que la superioridad de cualquier categoría tiene algo que ver con su masculinidad y que la femeninidad implicaba inferioridad.

Para los autores patrísticas, Eva, como mujer, representaba, metafóricamente $-y$ realmente--la sensualidad, percepción de los cinco sentidos, irracionalidad, imaginación, fantasía y todos los aspectos de la condición human asociados con la corporealidad y mortalidad. La separación de la carne del espíritu, el cuerpo del alma o los sentidos de la mente racional están prestados para describir las relaciones y diferencias entre hombre y mujer. Estas ideas funcionan como dicotomías inevitables que informan las dualidades neoplatónicas.
Aunque se están explicando asuntos espirituales, la exégesis patrística y los métodos alegóricos exigen que las metáforas sean traídas del mundo material. Es mi contención que estas imágenes y metáforas llegan a ser tomados literalmente y fueron transmitidos de comentario a comentario por toda la Edad Media y perduraron durante los Renacimientos cuando influenciaron a los humanistas y poetas del Renacimiento Inglés.

El tema de las teorías y posibilidades para la educación de las mujeres durante este mismo período es parte de nuestra herencia de Europa Occidental: La cristiandad durante los siglos XIV-XVI. En este tema sugiero que podemos localizan las dicotomías que informan los prejuicios en la teoría de educación que, con mucha sutileza, perduran en una modalidad sumergida en el discurso y práctica para los que tienen ojos para verlos, como un espejo enterrado.

Este ensayo tratará, sin embargo, no solamente de las mujeres excepcionales —aunque es pertinente mencionarlas - sino de las teorías educacionales de los humanistas ingleses, italianos, franceses y españoles de este período ya que ellos formaron nuestras actitudes actuales, prestando siempre de los antiguos y contemporáneos.

De hecho, era el objetivo de los humanistas ingleses producir, por medio de la educación, "una élite de aristócratas formados en 
la poesía, la historia y la filosofía del mundo antiguo, e imbuidos con el deseo de involucrarse en el servicio público" [Roberto Weiss, Humanism in England During the Fifteenth Century (Oxford, 1941), p. 179 [traducción propia].]

Pero existe otra faceta de este fenómeno de las teorías educacionales: el estado de la educación en su aplicación al sexo femenino aquí en la tierra. Esta examinación podría subrayar la adherencia a las imágenes del femenino e iluminar el trasfondo cultural contra que los autores masculinos hicieron burla de la ignorancia forzosa y la sensualidad de las mujeres.

Creo que se puede ilustrar que si humanistas ingleses y europeos como Erasmo de Rótterdam, Dr. John Colet y Juan Luis Vives abrazaron actitudes ambiguas hacia mujeres, aun cuando avanzando la esperanza para una educación en los artes liberales para mujeres. Podemos ilustrar aun mas claramente estas actitudes si nos enfocamos en John Skelton, el sacerdote y poeta de la corte del rey Enrique VII, orator regius y poeta laureado de las Universidades de Cambridge y Oxford, tutor y capellán para el futuro Rey Enrique VIII, en su poesía bella y alegre de elogio a las mujeres, con un tinte simultáneo de misoginia como la expresión racional de las actitudes de su tiempo.

Los humanistas ingleses principios del siglo XVI parecen adherir, en sus expresiones publicadas e impresas sobre sus teorías educacionales, a las sospechas expresadas en los escritos patrísticas sobre asuntos femeninos, especialmente en su preocupación casi histérica sobre la castidad femenina. Los Padres de la Iglesia (desde Orígenes hasta San Agustín) parecen combinar la naturaleza de la mujer con su sexo físico, como si fueran la misma cosa. Además asumieron el control, por medio de la castidad, de la actividad sexual como amonestación principal y primaria que, a la misma vez, pues, la castidad era la virtud más excelente que los humanistas podrían encomendar a las mujeres de su sociedad.

Ahora, en cualquier filosofía basada en jerarquías, inferioridad implica sujeción. Así, vamos a revisar las teorías y prácticas humanistas sobre el estado general de la educación antes de avanzar al contraste de la educación de hombres con la teoría y práctica educacional propuesta por los humanistas para mujeres del Renacimiento, principalmente en la Inglaterra de los reyes Enrique VII y VIII.

Indagando, como primera premisa de la examinación de las teorías educacionales, debemos ver algo del nivel de alfabetización en Inglaterra de estos tiempos. Se han formulado y publicado muchas opiniones sobre la cuestión de la amplitud y profundidad de alfabetización en la Inglaterra del siglo $\mathrm{XV}$. Roberto Weiss declara que "la erudición inglesa durante el siglo XV fue prácticamente el monopolio 
de eclesiásticos" (Roberto Weiss, Humanism in England During the Fifteenth Century (Oxford, 1941) p. 179. [traducción propia]). De otro modo, Joan Simon razona que "si la nobleza laica [del siglo XV] hubiera sido tan analfabeta como muchos insinuaron, el clérigo habría sido el maestro en lugar de lo que era: el sirviente del estado" (Joan Simon,
Education and Society in Tudor England (Cambridge, 1966) p. 6. [traducción propia]. Simon argumenta que se dio una ampliación de educación entre esferas más y más grandes. A la misma vez, C.L. Kingsford también argumenta para educación ampliamente distribuido entre la población en base de los siguientes argumentos:

Ha habido demasiada ansiedad de menospreciar la cultura y la civilización de la época [i.e., siglo XV]. Ciertamente, la capacidad de leer y escribir ya no era una habilidad restringida a la clase clerical. Las esposas y hermanas de los gentlemen rurales muchas veces pudieran escribir igual como sus esposos y hermanos, y ellos y sus sirvientes, ambos, pudieran $y$, en general, sí mantenían las cuentas de la casa.

C.L. Kingsford, Prejudice and Promise in Fifteenth century England (Oxford, 1925) p. 35 [traducción propia]

Es interesante examinar, yuxtapuestos, estas evaluaciones del estado de alfabetización en Inglaterra durante el período bajo consideración, porque demuestran cuán poco sabemos sobre la práctica real e histórica de las teorías educacionales, si tan notables eruditos especialistas como Weiss, Simon y
Kingsford evalúan la situación en tan distinta manera $-y$ también difieren con gente de hasta más alta calibre en el campo de historia medieval y la historia de la modernidad temprana, tales como J. H. Hexter y Lawrence Stone. Considérense las siguientes observaciones de Lawrence Stone sobre el tema:

No cabe duda de que algunas familias medievales de la aristocracia menor, así como la reconocida familia Paston, tomaron una educación desde los libros con mucha seriedad; pero ellos eran una familia excepcionalmente educada —así la sobrevivencia de su correspondencia en general... La escasez extrema de la sobrevivencia de las cartas y correspondencia sugiere que la nobleza y la 
aristocracia menor no pudo escribir, y presumiblemente no sintieron ninguna falta a causa de eso.... Es notable que en 1547 se pensaba que era importante insertar en una ley una cláusula que extendía el beneficio de clerecía a gentes que pudieran leer, $y$ tan tarde como durante el reinado de Elizabeth, había un consejero de su círculo de consejeros, el primer conde de Pembroke, quien no sabía leer ni escribir y quien ciertamente tenía la más grande dificultad en el esfuerzo de firmar documentos oficiales.

Lawrence Stone, Crisis of the Aristocracy (Oxford, 1965) p. 675 [traducción propia]

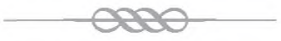

Ahora, G.W.O. Woodward, en su obra, 1485-1603: Reformation and Resurgence, England in the Sixteenth Century (Londres, 1963), se declara de acuerdo con Stone que, principios del siglo XVI, los aristócratas todavía eran de la opinión que la habilidad de leer y escribir no eran actividades apropiadas para los de la aristocracia. Además, Norman Davis, en la introducción a su edición de The Paston Letters [esto es, la correspondencia de la familia
Paston], parece estar de acuerdo con la postura de Kingsford, cuando declara que "el nivel de competencia en la habilidad de escribir entre tantas personas tan temprano en la historia de la habilidad de escribir cartas en Ingles, es muy notable" (Op. Cit., Oxford University Press, 1963), p. xvii [traducción propia]). Aunque, una observación más de Davis tiende a sugerir que las mujeres Paston no eran tan eruditas como algunos han asumido:

Las mujeres, en su mayoría, no escribieron por su propia mano y pudieran haber tenido ayuda de los clérigos, quienes escribieron a su dictado. Pero la consistencia de estilo que corre por todas sus cartas demuestra que, esencialmente, las palabras eran de ellas.

Davis, Op. Cit., p. xvii [traducción propia]

J.H. Hexter, sin embargo, documenta la observación de un tal Richard Pace, diplomático de la corte inglés, humanista, reconocido y eminente, quien sostuvo una conversación con un aristócrata inglés quien se expresó en la siguiente manera: que el estudio era para rústicos porque ser educado-o sea, que se pudiera leer 
y escribir-coincidió con la provincia de los clérigos eclesiásticos paupérrimos. La conversación con Pace termina con que el aristócrata se expresó que "prefiere que su hijo sea colgado por el cuello [i.e., ejecutado] en lugar de ser un erudito" J.H. Hexter, "The Education of the Aristocracy in the Renaissance," en
Reappraisals (Londres, 1961) p. 37 [traducción propia]).

Hexter, expresando opiniones opuestas a los de Stone, argumenta no para un "decaimiento" o "crisis" de la aristocracia, si no a favor de la posibilidad de un "reconstrucción" de la misma:

Comenzando en algún momento durante el reinado de Enrique VIII, los hijos de la nobleza de Inglaterra con títulos, comienzan a acudirse en masse a las torres de erudición clerical, las universidades inglesas.

Hexter, Op. Cit., p. 37

A la misma vez, G.W.O. Woodward supone que

A principios del siglo XVI, e incluso antes, la clase dominante políticamente de los terratenientes rurales habían mantenido una opinión de desprecio hacia la erudición descle los libros y aun hacia las habilidades elementales de leer y escribir en el sentido que consideraban estas habilidades eran apropiados solamente para clérigos y no para los de la aristocracia. Las actividades consideradas apropiadas para un gentleman —así lo creían-eran los asociados con la guerra y la caza.

Woodward, Op. Cit., p. 27

Estas opiniones y hallazgos nos presenta una gran confusión de opiniones entre los eruditos más eminentes de este campo, quienes difieren en el entendimiento de la supuesta apreciación o falta de apreciación para la lectura y escritura como educación - hasta el punto que dejaron la composición literaria completamente fuera del cuadro. Una conclusión segura -aunque cínica- es que nos falta mucha investigación $y$, por el momento, no sabemos el estado de la alfabetización en la Inglaterra de los siglos XV y XVI. Por lo tanto, entonces, aunque es una proposición peligrosa, pongamos, por el momento, la realidad histórica en segundo lugar y examinaremos solamente las teorías educacionales de los humanistas ingleses para ver qué recomendaban para los hombres y mujeres. 
En teoría, el objetivo de los humanistas ingleses durante el Renacimiento en el Norte que se inclinaba hacia el humanismo cristiano, era formar un varón casto y educado para tomar las riendas del gobierno. Los humanistas ingleses del siglo XV fueron principalmente conformado por los integrantes del Círculo de Sir Tomás Moro e incluían al Dr. John Colet, a Erasmo de Rótterdam (quien pasó un buen parte de su vida en la casa de Moro en Inglaterra), al Dr. Thomas Linacre y a William Grocyn. A la misma vez, había otros personajes que debemos incluir, como el poeta laureado y orator regius, John Skelton, un sacerdote que era tutor al joven Enrique que iba ser rey después de la muerte de su hermano, Arturo. Y el filósofo-teólogo español, si lo podemos incluir, Juan Luis Vives, Capellán de la reina Catalina de Aragón, posteriormente, esposa de Enrique VIII. Vives, así como Moro y Erasmo, publicó sus tratados en latín e inglés en Brujas y Londres.

Este grupo estaba compuesto, en gran parte, por teólogos conservadores, quienes no rechazaron el escolasticismo, como lo hicieron los humanistas italianos. En Inglaterra, los humanistas, de otro modo, agregaron al escolasticismo el New
Learning (la Nueva Erudición) que era principalmente el estudio del griego y la exégesis de los Padres de la Iglesia, que deseaban poner al servicio de la Iglesia Católica de Inglaterra y de toda Europa. Esto se entiende porque Inglaterra era todavía católica y este círculo, además del propio Skelton, deseaba entrenar las facultades de razón, contemplación y juicio para servir al estado en la corte.

La educación que ellos proponían, en general, para esta clase de hombres que iban a tomar las riendas del poder, incluía la inculcación de estudios de los clásicos latinos y griegos y el fomento de actividades virtuosas como valentía, justicia, prudencia, cortesía, magnanimidad y "el deber público de devoción, sin pensar en si mismo, a los mejores intereses del Estado..." (así escribió el resplandeciente humanista Richard Pace en su obra De Fructu (Basle, 1517), publicado en edición facsímile por F.J. Furnivall en Londres, 1886, pp. xii-xiii [traducción propia]).

Las cualidades a fomentar en estos hombres eran las virtudes públicas, activas y sociales. Los ideales humanistas que se proponían inculcar en estos estadistas eran los siguientes, siguiendo, obviamente, a Cicerón:

La primera distinción, se admitieron, era la virtud, es decir, que los estudios deberán contribuir a los méritos personales sobresalientes, y fomentar las habilidades benéficas acciones a favor del estado, porque un hombre pudiera practicar las virtudes privadas toda su vida y todavía no ser digno de 
nobleza, porque la virtud que era de la esfera privada era de una cualidad restringida en su influencia, mientras que la virtud que era apropiada para la nobleza era pública, y confirió beneficios al estado entero.

Ruth Kelso, Doctrine for the Gentleman of the Renaissance (Illinois, 1919) p. 13 [traducción propia].

Pero, ¿qué es que recomendaron a las mujeres? No es necesario aquí documentar los siglos durante los cuales las mujeres de todas clases no recibieron más educación que instrucción en la castidad, el silencio, obediencia y el trabajo de ama de casa. Nada se dice en las teorías sobre la educación de mujeres sobre la virtud pública, nobleza o servicio al estado. Habían muchas virtudes masculinas, pero la única virtud femenina era la castidad. Juan Luis Vives, quien escribe directamente a la reina Catalina de Aragón, insiste, en su obra, The Instruction of a Christian Woman, "Fyrst let her understande that Chastite is the principall vertue of a woman, and counterpeyseth with all the reste..." (Bruges, 1523, e impreso de nuevo en Londres, 1541?) sig. Jiiiv). La traducción de esta selección reza así: "En primer lugar, ella deberá entender que la virtud principal de una mujer es la castidad, que pesa más que todas las demás [virtudes].]

Ahora, la castidad es una virtud que se aplica principalmente al cuerpo, o a la carne. La carne, o cuerpo, según enseñaron los $\mathrm{Pa}$ dres de la Iglesia como Orígenes, San Jerónimo y San Agustín —es gobernada por la razón inferior (ratio inferior), la parte femenina del alma, o ser humano en la concepción tripartita del alma afirmada por San Agustín en De Trinitate y en todas sus obras. La ratio inferior se encarga de administrar y controlar el cuerpo para el bien y salud del alma.

El ejemplo principal de Hugo consiste en un comentario sobre el versículo del tercer capítulo del Libro del Génesis, que declara que Adán y Eva, después de la Caída, "cosieron delantales para si mismos." Hugo cita a Eva como el emblema de la parte inferior y femenina del alma y es por eso que no nos debe sorprender que siga la tradición que asocia a Eva con los artes de coser e hilar y con el trabajo de la rueca.

Tomemos un pequeño desvío aquí para presentar, como evidencia de la aplicación literaria de esta teología: un ejemplo del siglo XIV (Giovanni Boccaccio), uno del siglo XVI (John Skelton) y uno del siglo XVI (Erasmo de Rótterdam).

El humanista italiano Giovanni Boccaccio, a finales del siglo XIV, en su obra De Mulieribus Claris (Sobre Mujeres Sobresalientes) da cré- 
dito a Eva para el descubrimiento del arte de hilar con la rueca: "Ibi egregia mulier...colo nere adinvenisset, sepias dolores partus experta est..." (Tutte le Opere di Giovanni Boccaccio, de edición Vittor Branca (Roma, 1967)).

Otro ejemplo de la influencia de estos pensamientos en la Inglaterra del siglo XV es el poema de John Skelton, sacerdote y tutor al joven rey Enrique VIII, The Garlande of Laurell, donde Skelton presenta a la Condesa de Surrey y sus damas en la actividad silenciosa de tejer y bordar la guirnalda de hojas de laurel para la coronación de Skelton como poeta laureado, mientras que él las insulta con eruditas palabras en el poema. Este retablo se puede ver como la representación de la tradición que asociaba el sexo femenino con los artes prácticos y mecánicos y asociaba, a la misma vez, el sexo masculino con racionalidad, erudición y éxitos literarios e intelectuales.

El tercer ejemplo es de los principios del siglo XVI, Erasmo de Rótterdam, escribiendo en su Christiani matrimonii institutio, declara que "la rueca y los instrumentos para hilar son, en verdad, los instrumentos de todas las mujeres y apropiados para ellos con el propósito de evitar la pereza" (Basel, 1526, capítulo 17) [traducción propia].

Además, la gran mayoría de las representaciones iconográficas en la Edad Media y el Renacimiento de toda Europa, de Eva la muestra con la rueca en la mano. En los ejemplos coleccionados en el Princeton Index of Medieval Art, Eva aparece en la Iglesia de Todos los Santos en Bledlow, Inglaterra como parte de un retablo intitulado "Adán y Eva recibiendo sus tareas". En este retablo, Eva recibe la rueca. Eva se encuentra en la misma postura con la rueca en la Catedral de Erfurt en Alemania, en la Catedral de Ferrara en Italia y en la Catedral de Chartres en Francia. Descanso mi caso.

A las mujeres, en general, siendo las representantes de las facultades inferiores del alma humana en la tradición agustiniana —es decir, de toda la tradición patrística de Europa Occidental- se les encomienda, ad nauseum, ser educadas en los artes aplicados, adulterados y mecánicos - no en la sabiduría, filosofía o los artes liberales.

Pero hay que decir que las mujeres inglesas dieron vuelta a esta restricción a favor del desarrollo comercial de su nación (no obstante las burlas de Ben Jonson en su obra Volpone). El bordado inglés llegó a ser el arte fino equivalente a la pintura y la literatura (cf. el tapiz Bayeux hecho en Winchester en Inglaterra).

Regresando al tema, como hemos visto, la naturaleza femenina no fue considerado como principalmente racional, o dada a la reflexión o contemplación. Siglos de pensamiento patrístico en Europa Occidental no escaparon a los filósofos y teóricos en educación, 
quienes dictaron como se debe educar a las mujeres de todas las clases y niveles. La asociación de femeninidad con la carne o cuerpo, con la inferioridad de la carne o el cuerpo, fue vinculado con la noción de la fragilidad mental de mujeres. Con esta definición de "la mujer" en mente, la mayoría de pensadores emitieron instructivos avisando fidelidad, constancia, humildad, vergüenza y prudencia, sobriedad, constancia, modestia y, sobre todo, el silencio. La virtud principal para todas las mujeres, que fue, durante siglos, reforzada con cinturones de castidad o la infibulación, era la castidad: Castitas.

Debemos profundizar un momento en este concepto de castidad, pilar de la educación encomendada a las mujeres. La castidad es una virtud moral que modera el apetito sexual. Hay dos clases de castidad: la de los celibatos, que requiere la abstención de toda delectación carnal voluntaria; y hay la castidad de personas en el estado de matrimonio, que involucra la fidelidad al esposo o a la esposa e incluye la moderación en el pago de la deuda matrimonial. Pero además no permite que uno pueda participar en la delectación carnal voluntaria porque la procreación es el único fin de la deuda matrimonial. Finalmente, entonces, la castidad es una virtud que regula y controla el cuerpo, sus apetitos sexuales y las actitudes mentales que resultan de la sexualidad del cuerpo (Dictionnaire de theologie catholique, eds. Vacantet Mangenot (Paris, 1905), p. 2320. [traducción propia].

$\mathrm{Si}$ la castidad es suficiente, entonces, la educación no es necesaria. Una educación en la obediencia y el silencio no requiere la práctica de las artes liberales. $\mathrm{Ni}$ requiere saber leer ni escribir. Pero sí nos dirige en la dirección de las artes aplicadas, y, encima de todo, los artes de cuidar una casa. En 1590, Robert Green todavía pudo estar de acuerdo con Juan Luis Vives cuando escribe lo siguiente:

Chastity is the flower of manners, the honour of the body, the ornament and splendour of the female sexe, the integrity of the bloud, the faith of their kinde, and the proclaimer of the sincerity and candour of a faire soule.

[La castidad es la flor de los modales, el honor del cuerpo, el ornamento y esplendor del sexo femenino, la integridad de la sangre, la fe de su naturaleza, y lo que proclama la sinceridad y fidelidad de un alma bella.]

Robert Greene, "The Royal Exchange", en Works, ed. A.B. Grosart (1881), Vol. VII, p. 231. [Traducción propia] 
Todo el mundo sabía, aunque no conocían los argumentos teológicos que apoyaba el hecho, que mujeres sufrieron el dolor y tristeza mensual, mas dolor y tristeza al dar luz en el macimiento de los hijos, y un constante y generalizado fragilidad que las hizo propensas a la debilidad y enfermedad-todo eso porque Eva había pecado. Pero ¿Qué, poniendo a un lado las teorías filosóficos y teológicos, eran las realidades históricas antes de 1500 que dio credibilidad a estas teorías y creencias populares?

Ruth Kelso explica que:

Las pruebas de la inferioridad natural de la mujer se encuentran en su sujeción a los hombres, su dependencia económica y legal y su exclusión de puestos públicos.

Ruth Nelson. Doctrine for the Lady of the Renaissance (IIlinois, 1956) p. 13. [traducción propia]

Durante los tiempos del rey Eduardo I en el siglo XIII en Inglaterra, se habían eliminado los derechos legales de mujeres con el argumento legal de que formaban parte de la categoría de judíos, excomulgados, leprosos, lunáticos e idiotas. Mujeres gozaban de pocos derechos, salvo por medio de un protector o diputado. (Pollock and Maitland. History of English Law
Before Edward I, Vol. I (Cambridge, 1895) p. 83 [Traducción propia].

$\mathrm{Su}$ inferioridad natural fue comprobada con su incapacidad de tener o transmitir el estado de nobleza en nombre, de la propiedad a sus hijos. Estas realidades históricas son la traducción en la práctica de pronunciamientos así como los de Pedro Lombardo, el autor del gran libro de texto universitario de toda la Edad Media:

Mulier autem gloria est viri. Mulier est ipsa sensualitas, Quae bene significatur per mulierem, quia en femina $\mathrm{Na}$ turaliter praevalet, quae subserviendo gloria est rationis. Magna Glossatura. Patrologia Latina 1291: 1634a

Ahora, al llegar los siglos XV y XVI, los asuntos habían cambiado:

Una mujer podía presentarse en una corte de leyes como el representante legal de su esposo, pero una mujer casada no podía presentarse como dependiente en un proceso legal sobre su propia propiedad o en materia de su propio nego- 
cio, aun si era femme sole [i.e., estado de una mujer sola con su propio negocio]. Una mujer casada no podía, en general, escribir un testamento para heredar sus bienes sin el consentimiento de su esposo, pero sí podía actuar como ejecutor o representante legal de su esposo para grandes tierras. Estas reglas de ley reconocían sus habilidades, pero no sus derechos como individuo.

Pearl Hogrefe, "The Legal Rights of Tudor Women and their Circumvention by Men and Women," Sixteenth Century Journal III (abril, 1972) pp. 99-100, donde está resumiendo a Sir William Holdsworth, A History of English Law (Londres, 1945), Vol. V, p. 315. [traducción propia]

En los tratados teológicos del período, consideramos al Dr. John Colet, quien actuó como guía espiritual para Santo Tomás Moro, además de teólogo de la época de los Tudores, fundador de la Escuela de la Catedral de San Pablo (en la cual no se admitía a las niñas). Al escribir sobre el tema de la Iglesia Católica en Inglaterra, hacía la relación jerárquica de hombres y mujeres en el mundo sublunar. Lo siguiente es una selección de The Lectures on Corinthians, presentado por Colet como homilía en la St. Paul's Cathedral en 1496:

For there is nothing masculine in a higher ninefold order that has not its feminine in a lower. in the higher, all things are masculine, in the lower, feminine; in the lowest, most feminine of all.

[Porque no hay nada masculino en un orden superior de nueve escalones que no tenga su [parte] femenina en el inferior. En el escalón superior, todas las cosas son masculinas, en el inferior, femeninas; en lo inferior de todo, lo más femenino de todo.]

John Colet. Lectures on Corinthians, Ed. Lupton (Londres, 1867) p. 131 [traducción propia]

En la filosofía y teología, la carne deberá servir al espiritu y eso significaba, en la práctica, la sujeción de la mujer, quien repre- sentaba —quien era- la carne y la sensualidad. La Iglesia dijo que era así y todo la demás en la sociedad siguió su determinación. 
Siendo una criatura de vida privada, dominado por el cuerpo y con ninguna posibilidad para una vida pública (que era una amenaza a la castidad), teorías de la educación de la mujer fueron conformados en teoría para su capacitaron al silencio y obediencia. Durante los primeros catorce o quince años de su vida, iba ser entrenada para la obligatoria sumisión a la decisión de su padre sobre quien iba ser su esposo -a quien, después, iba someterse en castidad, obediencia y en silencio por la demás de su vida.

Pero eso es solamente la teoría. La realidad era mucho más colorida y llena de tensiones. Aunque tanto hombres como mujeres escucharon las exhortaciones de la Iglesia que debían ser castos, para las mujeres, la castidad era la virtud principal y casi exclusiva. La castidad sirvió una función muy práctica en lo social y económico en asegurar la paternidad única en la herencia del hombre en nombre y propiedad. La castidad, como hemos visto, es una virtud corporal -es decir, gobierna el cuerpo y la vida mental privada que deberá controlar al cuerpo por el bien del espíritu. Las mujeres no tenían vidas públicas $y$, por lo tanto, no necesitaban las virtudes públicas, salvo silencio y una preocupación para su reputación. Eso es la teoría y lo ideal. La realidad revela a mujeres como Leonor de Aquitania, a la Esposa de Bath en Los Cuentos de Canterbury, a Porcia en El Mercader de Venecia, la reina Catalina de Aragón y la reina Isabel I, para mencionar sólo a algunas.

En resumen, el razonamiento teológico de los Padres de la Iglesia redujo a la mujer a una criatura física y sensual con una mente que tendía por naturaleza y por la indoctrinación forzosa hacia la vida del hogar. (Para los lectores que piensan que las cosas cambiarían después de Descartes y la Ilustración Europea, debemos mencionar las opiniones de Jean-Jacques Rousseau en su documento sobre la educación de la mujer en el siglo XVIII, La nueva Eloísa, en que declara que se debe colocar el yugo en el cuello de las niñas a una temprana edad para que, en la medida que van creciendo, ya no lo sientan).

Bueno, las expectativas se fueron cumpliendo en el hecho de que las mujeres, constantemente descritas, elogiadas o culpadas en estas dimensiones y criadas con las limitaciones legales, sociales y morales que resultaron de esta premisa, se conformaron con meterse en el patrón, el molde preparado para ellas descle San Jerónimo, San Agustín y todos los demás publicados en la Patrologia latina.

$\mathrm{Y}$ siguieron de estas premisas los refuerzos legales, sociales y políticos para la sujeción. Pero como la Iglesia en la Edad Media y durante los Renacimientos, era central a todas las esferas de la sociedad, creo que se puede atribuir una cierta causalidad para la 
condición propuesta por la Iglesia y sus pensadores. De acuerdo con eso, podemos ver evidencias de esta influencia cuando Juan Luis Vives, uno de los humanistas más iluminados del Renacimiento Inglés (aunque era español quien había llegado a Inglaterra como Capellán a la Reina Catalina de Aragón), y uno que prescribió el programa educacional más progresista para mujeres en, talvez, quince siglos, declara lo siguiente en su tratado publicado en Londres en 1541) Instruction of a Christen Woman [Educación para una Mujer Cristiana], escrito para la instrucción de la Reina y dedicado a ella. Sería interesante saber que opinaba la Reina sobre lo siguiente:

Womans thought is swyfte, and for the moste part vnstable, walking and wandering out from the home, and some wyll slide, by the reason of it [sic] owne slipernes, I wote not how far.

[Los procesos de pensamiento de la mujer son rápidos, y, en general, inestables, caminando y vagabundeando fuera del hogar, y algunas se deslizarán, por razón de esta cualidad de deslizamiento propia a ellas, no sé cuán lejos.]

Juan Luis Vives. The Instruction of Christen Woman (Brujass, 1523; reimpreso en Londres, 1541), Sig. Biiiv [traducción propia]

Pero nos presenta la problemática de las consecuencias históricas actuales y las implicaciones de este complejo de premisas. Uno podía asumir que, con la debilidad física, moral e intelectual como su herencia, y con la castidad, obediencia y silencio como las virtudes encomendadas, que la esfera de sus actividades en la Iglesia, el hogar, con el esposo y los hijos, que no hubiera existido ningún ímpetu a educarla en los artes liberales. Y, por supuesto, eso era el caso-las mujeres fueron específicamente excluidas de las universidades.
Los humanistas ingleses - por lo menos, dos de ellos- propusieron la educación para mujeres como parte de su plataforma para reforma-y eso en una Inglaterra Católica del siglo XV. Peral Hogrefe, en su excelente libro, The Sir Thomas More Circle, explica los teorías educacionales expresadas en siete de las obras de mayor importancia en Inglaterra durante este período e incluye una discusión de unas cartas y correspondencia de este círculo que incluía a Juan Luis Vives, Erasmo, Colet, Grocyn, Linacre, Rastell y el obispo Fisher, futuro 
mártir con Santo Tomás Moro. Se expresó, entre ideas progresistas, lo que Hogrefe denomina "una dualismo curioso" en, por ejemplo, el deseo de promover la educación para las mujeres y "su celo fanático sobre el tema de la castidad."

Las teorías avanzadas por el círculo de Moro avanzaron argumentos para una educación para mujeres más allá de cómo coser, cocinar y supervisar a los sirvientes-aunque los temas de la castidad y obediencia nunca pierdan su pre-eminencia como virtudes femeninas y correctivos para una naturaleza deslizante e inestable.

Examinamos un poco el tratado de Juan Luis Vives sobre la Instruction for a Christen Woman, porque él, con Tomás Moro, era el teórico sobresaliente sobre educación. Dedicado a la reina Catalina, las ideas de este tratado, por lo tanto, serían completamente ortodoxas en sus puntos de vista sobre la mujer. Como Capellán a una reina altamente erudita, y como tutor de su joven hija María, posteriormente reina de Inglaterra, sus propuestas pueden ser considerados más iluminadas que otros autores.

Vives es un filósofo que tiene simpatía por la Reina Catalina y por todas las mujeres de los tiempos antiguos. Pero sufre de una mente fuertemente dividida, como hemos visto, cuando habla sobre el tema de la naturaleza de la mujer en general. Desea ardientemente que sean educadas, pero, a la misma vez, expresa temores sobre las consecuencias de esta medida. Su prosa está llena de lástima por la situación de mujeres quienes tienen siempre que cuidar el hogar, cocinar, cuidar a niños, supervisar a sirvientes y siempre estar cosiendo para reparar la ropa de la familia. Dice Vives:

What a torment were it for a man to do thes thinges? A man wold rather leaue all, \& dwell in a desert, then to dwel in such misery and bondage.

[¿ No sería una angustia para un hombre tener que hacer estas cosas? Un hombre desearía dejar a todo e ir a vivir en un desierto en lugar de vivir en tal miseria y servidumbre.]

Op Cit., prefacio.

En el mismo prefacio a este tratado, Vives presenta a sus lectores pronunciamientos filosóficos sobre la clase de educación que él cree que mujeres deberán estudiar, opuesta a lo que prescribe para los hombres:

Though the precepts for men be innumerable: yet women may be informed with few words. For men must be occupied both at home and abroad, both in their owne matters 
and for the common weale. Therefore it cannot bee declared in fewe bookes, but in many and long, how they shall handle themselves in so many and divers thinges. As for a woman shee hath no charge to see to, but her honestie and chastity. Wherefore when she is reformed of that, shee is sufficiently appointed.

[Aunque los preceptos para los hombres son numerosos, las mujeres, sin embargo, podrían ser instruidas en pocas palabras. Es que los hombres tendrán que ser ocupados en el hogar y fuera del hogar, ambos, y en sus propios asuntos igual como con los asuntos del estado. Por lo tanto, no se puede poner en pocos libros, si no en muchos libros largos, como deberán comportarse en tantas y variadas asuntos. Ahora una mujer quien no tiene estas preocupaciones, solamente su honestidad y su castidad. Por lo tanto, cuando ella es congruente con eso, es suficientemente instruida.]

Op. Cit. Prefacio.

Vives escribe elocuentemente a favor de educación para mujeres y elogia la erudita reina Catalina y las hijas de Tomás Moro juntas con, por ejemplo, Hortensia, hija de Hortensias, el orador, por ser elocuentes. Sin embargo, dos páginas después, en el mismo tratado, Vives declara que "As for eloquence, I have no great care, nor a woman nedeth it not." [En la cuestión de elocuencia, no me interesa mucho que una mujer la tenga, porque no la necesita.]. [Op Cit., Sig. Ciiiiv].

Vives, en esta obra, expresa claramente que las mujeres no deberán ser maestras ni profesoras, porque en eso iban a usurpar la autoridad de los hombres. Deberán seguir las enseñanzas de San Pablo de escuchar en completo silencio. $Y$ eso porque Eva con sus falsas opi- niones, sensualidad e imaginación usurpó la racionalidad del primer hombre, Adán, y causó la Caída de la humanidad, ideas que encontrarán su plena expresión en El paraíso perdido de John Milton, ciento cincuenta años después cuando Milton declara que el Pecado Original, era "uxoriousness" —el hombre (Adán) que, equivocadamente, obedece a la mujer (Eva). Vives recomienda que una mujer erudita deberá quedarse en casa donde pocos la puedan ver y donde ninguno la pueda escuchar. [Op Cit., Sig. Biiir] Termina con aseverar que, aunque el hombre es creado en el imagen de Dios, la mujer sola no lo es: su pensamiento consiste en la fantasía e imaginación [léase, ratio inferior] y tiene que ser controlada por la razón mas alta del hombre [léase, ratio superior]. 
Hay, dice Vives, una ocupación que recomienda con todo corazón a la mujer, y eso para guardarlas de la pereza y de protegerlas de su propia naturaleza que es muy dada a "pleasure and daliance" [placer y vagabundeo]: hilar, coser, tejer. Vives asocia a mujeres que desean enseñar con Eva y sus opiniones falsas que causó la Caída. El antídoto es, declara, "the dressynge of wolle hath ben euer a honest occupation for a good woman" [Trabajando con la lana ha sido siempre una ocupación honesta para una buena mujer]. [Op Cit.] Vives nos da un recordatorio con ejemplos: San Jerónimo aconsejaba a Paula en sus cartas a ella que debe "...handel wolle...to lerne to dresse it,... and turn the spindel, and draw forth the thred with her owne fingers...." [... maneja la lana....aprende a cuidarla... y dar vuelta a la rueca y jalar los hilos con sus propios dedos] (Op Cit., Sig. Biiir). Vives nos trae a la memoria a Samuel, Salomón y Terencio, además de Penélope, a quien elogia por pasar veinte años de su vida tejiendo. Este labor, dice Vives, significa castidad. Según la tradición de muchos siglos, Eva inventó el arte de hilar, o, más bien, le fue asignada esta labor cuando ella y Adán cayeron de la gracia de Dios en el Edén.

En el asunto de la lectura, nos instruye Vives, la madre, esposa e hija puede leer las Sagradas Escrituras y obras de los filósofos, porque la erudición es un baluarte para la castidad. La virginidad, declara Vives, es indispensable para la educación. Además, las mujeres NO deben leer romances, porque son trucos para practicar el adulterio. Están especialmente prohibidos Boccaccio, Poggio Bracciolini y los poetas griegos y latinos. La recomendación es específicamente leer a los cuatro evangelistas, Los hechos de los apóstoles, los santos Cipriano, Jerónimo, Agustín, Ambrosio, Crisóstomo, Gregorio, etc. "Yf she can reade, setter her hauae no bookes of Poetrye...". O sea, si persiste en leer poesía, el esposo debe quitarle todos los libros.

Pero eso es solamente el primer capítulo. Durante los aproximadamente 150 páginas que quedan, no hay mención de lectura: el enfoque de Vives en lo demás de su tratado, es exclusivamente en la obediencia en matrimonio. Ruth Kelso, en su estudio Doctrine for the Lady of the Renaissance (Illinois, 1956), explica que

El estudio más frecuentemente prohibido era la lectura de la poesía porque se asumió que era lo más amenazante a la castidad... La retórica causaba sospechas en el sentido que llevó a exhibiciones vanas de habilidades verbales que estaba en contra con la visión de una mujer que debe quedar en silencio. [Op. Cit. P. 31) 
Ahora, Vives también escribió un tratado titulado The Office and duetie of an husband (Londres, 1553) donde siempre elogia a mujeres eruditas y afirma que la mujer es tan razonable como el hombre, pero, dice, hay que ser claro: "the womans witte is no lesse apte to al thinges, than the man is:-shee wanteth but counsell \& strength" [la mente de la mujer no es menos apta que la mente del hombre:- a ella solamente le faltan consejo y fortaleza] (Op. Cit.) Pero a la misma vez, asevera que la mente de la mujer es "soft and delicate", "swift and vnstalbe" porque la mujeres son débiles, supersticiosas, temerosas, llenas de palabras y sus cabezas son una mezcla de emociones y pensamientos. Pero no solamente son las mujeres que tienen estas cualidades despreciables. Vives nos asegura que cualquier persona - hombre o mujer- que las tiene es "woman like".

En resumen, es obvio que las mujeres recibieron alguna clase de educación, pero era muy distinta de la que recibieron los hombres.

En contraste, leemos lo que dice Sir Tomás Moro cuando comenzó su escuela para mujeres donde las mujeres eran educadas en la misma manera que los hombres. En una carta a William Gonnell, Moro declara:

Ya que la erudición en las mujeres es un asunto nuevo y constituye una censura contra la pereza de los hombres, muchos atacan la idea con vehemencia y asigna a la literatura lo que es en realidad una falta de la naturaleza, pensando que los vicios de los eruditos ganar elogios virtuosos para su propia ignorancia.

Rogers. The Correspondence. No. 63 [traducción propia]

En su Utopia, Moro expresa ideas muy igualitarias sobre el papel de la mujer en su sociedad imaginaria: pueden ser soldados $y$ sacerdotes. Pero, examinando sus conclusiones más de cerca, podemos detectar las actitudes familiares de los escritos patrísticos, cuando Moro expresa su sospecha hacia la mujer sexualmente activa: las mujeres pueden ser sacerdotes solamente bajo la condición que sean viudas y ya pasada la edad de poder tener hijos. Se evidencian aquí sombras de San Jerónimo.

En el caso de la familia, Moro expresa pleno reconocimiento de la autoridad patriarcal: "The wyfes bee ministres to theyr husbandes...". [Wives deben cuidar a sus esposos] y antes de ir a la Iglesia en los días sagrados, Moro encomienda a las 
mujeres que las esposas deben "fall downe prostrat before their husbandes feete at home" [las esposas deben postrarse a los pies del esposo en la casa.) [Utopia, ed. ].H. Lupton (Oxford, 1895), pp. 156-7 [traducción propia].

Estas dos ideas representan la misma clase de dicotomía (iesquizofrenia?) que se encuentra en Vives -aunque Moro, especialmente en su escuela, no puede ser comparado con otros pensadores del Renacimiento inglés a causa de la asombrosa educación que ofreció a las mujeres, ejemplo iluminada de la cual es su propia hija, Margaret Roper.

Erasmo, de igual manera, elogia a Moro y expresa que es recomendable brindar una educación completa en los clásicos griegos y romanos a las mujeres. En este aspecto, vienen inmediatamente a la mente las mismos cuatro mujeres quienes críticos literarios he historiadores, ambos, siempre nos presenta como luminarias con habilidades intelectuales, quienes leen muchos idiomas, tradujeron libros, manejaron asuntos políticos, disputaron en lógica con elocuencia: La reina Catalina de Aragón, Lady Margaret Beaufort, Margaret Roper y la reina Isabel I.

Veamos primero a la reina Catalina, ya que hemos visto las opiniones de Vives en el libro que le dedica, para pensar en una comparación entre la teoría y la práctica o realidad de la situación de esta gran mujer. De hecho, Catalina era una de las personas más eruditas de su época. Pero no era inglesa y había recibido su educación en España antes de llegar a Inglaterra. Ella había sido instruida por su madre Isabel, sobre cómo bailar, dibujar, preciar música, cose e hilar, además de haber hecho estudios en heráldica, genealogía, equitación y halconería. Después de sus estudios en la Biblia y las vidas de los santos, ella leyó a los poetas cristianos como Prudencio y los Padres Latinos de la Iglesia: Ambrosio, Agustín, Gregorio y Jerónimo. Conoció bien el derecho canónico y civil y pudo hablar Latín clásico con fluidez y practicaba la diplomacia en este idioma.. Uno de sus biógrafos, Garrett Mattingly, cree que "Catalina apareció ante Erasmo y Luis Vives como un milagro de erudición femenina". [traducción propia].

Catalina habló en público en latín como parte de sus funciones como reina en ocasiones diplomáticas y tenía avanzadas habilidades en los asuntos del estado. Vives, sin embargo, insiste que hasta las reinas deberán aprender a cocinar, coser e hilar $-y$ es cierto que su educación había preparado a Catalina principalmente para ser una esposa.

En el interés de la brevedad, consideramos solamente una mujer más: Margaret Roper, hija de Santo Tomás Moro, casada con William Roper, quien escribió la primera biografía de su suegro.

Margaret ganó los elogios del propio Erasmo por su erudición. 
Gozaba, gracias a la visión de su padre, de una habilidad magnífica en los artes liberales que sobrepasó con creces la educación de la rejna Catherine. Dominaba el latín, el griego, la lógica, la filosofía, la teología, la matemática y la astronomía. Moro era el único que puso sus ideas sobre la educación de mujeres en práctica. Recordamos el importante comentario famoso de Margaret al rey Enrique VIII cuando le preguntó si ella era una erudita. Margaret respondió (según su esposo en su biografía de Moro): "Entre las mujeres, paso por ser una".

Sobre Margaret Beaufort, condesa de Richmond y Derby, madre del rey Enrique VII, debemos mencionar que conoció latín suficiente como para traducir al inglés la Imitatio Christi de Tomás de Kempis. Tradujo del francés al inglés la obra Mirroure of Golde for the sinfull Soule (impreso por Pynson en 1507). Escribió una obra original: "Ordinances and Reformations of Apparel for princes and estates with other ladies and gentlewomen for the time of mourning." Lady Margaret comisionó la fundación de Christ's College, Oxford, y escribió sus estatutos, que después fueron traducidos por otras manos al latín. Sus biógrafos, no obstante, escriben elogios de su habilidad con la aguja.

Ahora, Isabel I de Inglaterra (m. 1603) recibió una educación de los mejores en el mundo en sus estudios con Roger Ascham. Educada en Latín, Griega y los clásicos, tradujo La consolación de la filosofía de Boecio del latín al inglés y, desde su propia traducción inglesa, de nuevo al latín en el espacio de veinticuatro horas. La reina sabía hablar francés, alemán y latín y llevaba los asuntos diplomáticos de su reino en latín.

Pero había otras mujeres eruditas en la historia de Inglaterra. Un repaso de las mujeres escritoras, poetas y autoras de Inglaterra y el continente sería apropiado para finalizar. Consideremos a Christine de Pisan (1364-1429?), primera escritora francés, era una dama veneciana, hija de Tommaso di Benvenuto da Pizzano, Consejero a la República de Venecia, quien fue a vivir en Francia donde su esposo, Tommaso de Pizan era médico para el rey, Carlos $V$ de Francia. Ella quedó viuda muy joven en la corte francesa cuando murió su esposo, y ella tuvo que ganarse la vida escribiendo para criar a sus hijos en un país extranjero.

Christine, escribiendo en francés antiguo, ganó importantes anfitriones en la corte entre 1393 y 1412 con su obra La Cité des Dames (La Ciudad de Damas) y mas de 300 otras obras, incluyendo ataques contra el famoso y poderoso escritor Jean de Meung (autor de Le Roman de la Rose) porque despreciaba a las mujeres en este poema tan famoso. El argumento principal de sus muchas obras, con elocuente retórica en el siglo XV en Francia, era que mujeres pudieran participar en la vida pública y política de sus 
ciudades. Era, y es, muy reconocida y Simone de Beauvoir declaró que, con Christine de Pisan, veamos "la primera vez que una mujer tomó pluma en defensa de su sexo" (de Beauvoir: Épitre au Dieu d'Amour, 1949).

Ahora, regresando a Inglaterra y en orden cronológico, en el siglo XII, Leonor de Aquitania, esposa de Enrique II de Inglaterra y Francia y madre de Ricardo Corazón de León, sabía leer y escribir, funcionó principalmente como anfitriona de las Cortes de Amor donde escribieron poetas, hombres y mujeres. Lo mismo era el caso de su hija, Marie de Champagne, y la autora de las Lais, Marie de France. Todas ellas en el siglo XII en la mezcla de territorios que iban a ser Inglaterra y Francia, ambas. $Y$ tenemos los poemas de los aproximadamente cien poetas provenzales del siglo XII: Clara d'Anduza, la condesa de Die, y cientos de mujeres más, quienes nos dan a conocer sus nombres, como trovadoras en sus poemas occitanos.

Ahora, en Inglaterra y en el continente, un siglo anterior, escribieron monjas The Ancrene Wisse, reglas para abadesas en la gerencia y conducta de su vida monástica. La más famosa, por supuesto, era Hild, abadesa del Monasterio de Whitby en el norte, quien presidió el reconocido Sínodo de Whitby donde aceptaron la fecha para la celebración de Pascua en el calendario litúrgico establecido por Roma para la celebración de Pascua en lugar de la modalidad céltica de establecer la fecha - momento histórico enormemente importante.

Las abadesas Hroswitha von Gandersheim y Hildegard von Bingen, en lo que sería Alemania, son prolíficas en sus escrituras, su composición de música y drama y en el liderazgo de sus conventos, internacionalmente reconocidas por Roma y los papas contemporáneos.

La dama Julian of Norwich y Margery Kempe, visionarias, místicas y escritoras religiosas, ambas del siglo XV en Inglaterra, tuvieron que sufrir castigos de las autoridades legales y canónicas en los conflictos religiosos el siglo XV. Pero sus obras y sus vidas están disponibles en estudios recientes.

El Renacimiento inglés ha sido presentado casi convencionalmente, por críticos e historiadores literarios por lo menos, como una época de erudición floreciente en la fundación de escuelas, universidades e imprentas -en efecto, como un renacimiento de erudición. Al leer los recuentos de eruditos e humanistas italianos quienes visitaron a Inglaterra en el siglo XVI, se pudiera asumir que este era el caso. Pero las mujeres que sobrevivieron las teorías de educación propuestas para mujeres, son ejemplos que merecen nuestra atención.

En fin, la realidad sobrepasa las teorías retrógradas de los escritos y tradiciones que crecieron desde los filósofos y teólogos que son nuestra herencia de Europa Occi- 
\& dental. Aparecen los sorprendentes ejemplos de fuerza y diplomacia como los de Catalina de Aragón e Isabel I de Inglaterra y los brillantes ejemplos de Margaret Roper y

LECTURAS RECOMENDADAS:

Lectura recomendada [en la Biblioteca Florentino Idoate, S.J.]

Aries, Philippe. Centurias of Childhood: A Social History of Family Life (Nueva York, 1962)

Christine de Pizan. The Book of the City of Ladies (Nueva York, 1998)

Erasmo de Rotterdam. Obras Escogidas (Madrid, 1964)
Christine de Pizan. Por suerte, las bibliotecas están Ilenas de estudios de ellas como parte del esplendor de los Renacimientos. Sólo falta leerlos.

Hugo de San Víctor. The Didascalicon of Hugh of Saint Victor: A Medieval Guide To the Arts (Nueva York, 1991).

Mattingly, Garrett. Catalina de Aragón (Buenos Aires, 1959)

Vives, Juan Luis. Obras Completas (Madrid, 1947-1948)

Weir, Alison. The Life of Elizabeth I Nueva York, 1998) 